\title{
O CURRÍCULO DE MATEMÁtICA DA EDUCAÇÃo BÁSICA: UMA PERSPECTIVA DA CIÊNCIA, TECNOLOGIA E SOCIEDADE (CTS)
}

\section{DISSERTAÇÃO}

RODRIGUES, Mírian Ferminiano ${ }^{1}$

MACIEL, Maria Delourdes ${ }^{2}$

RODRIGUES, Mírian Ferminiano. MACIEL, Maria Delourdes. O currículo de matemática da Educação Básica: Uma perspectiva da ciência, tecnologia e sociedade (CTS). Revista Científica Multidisciplinar Núcleo do Conhecimento. Ano 05, Ed. 08, Vol. 06, pp. 80-96. Agosto de 2020. ISSN: 2448-0959, Link de acesso: https://www.nucleodoconhecimento.com.br/educacao/curriculo-dematematica

\section{RESUMO}

Para investigar pesquisas com foco no desenvolvimento de um currículo de Matemática na perspectiva da Ciência, Tecnologia e Sociedade (CTS), mapeamos dissertações e teses do banco de dados da Coordenação de Aperfeiçoamento de

${ }_{1}^{1}$ Doutoranda em Ensino de Ciências e Matemática: Universidade Cruzeiro do Sul, Mestre em Ensino de Ciências e Matemática: Universidade Cruzeiro do Sul (2008), Especialista em Designer Instrucional - SENAC/SP (2020), graduada em Ciências e Matemática: Universidade Camilo Castelo Branco (2007) e Pedagogia: Universidade Camilo Castelo Branco (1995).

2 Pós-doutorado em Educação: formação de professores pela Pontifícia Universidade Católica de São Paulo (2006).Doutorado em Educação (Psicologia da Educação) pela Pontifícia Universidade Católica de São Paulo (2001);Mestrado em Educação (Supervisão e Currículo) pela Pontifícia Universidade Católica de São Paulo (1995); Graduação em História Natural/Ciências Biológicas pela Universidade Federal do Rio Grande do Sul (1976). 
Pessoal de Nível Superior (CAPES), de 2003 a 2018. Um currículo CTS pauta-se pelo desenvolvimento de uma postura crítica dos estudantes acerca do papel da Ciência e das Tecnologias na Sociedade. Assim, o ensino de Matemática deve focar a construção do conhecimento matemático para além da mera aplicação de regras e fórmulas desconectadas dos contextos sociais, para que possa ser uma ferramenta de leitura, compreensão e intervenção no mundo em que os estudantes vivem e atuam. Fundamentados em Santos (2002), Sacristan (2000), PCN (1997) e BNCC (2017) e outros, realizamos uma pesquisa documental, de aspecto qualitativo. O conteúdo dos dados obtidos nas produções científicas foram analisados a partir de Bardin (2011). Encontramos 13 produções científicas (08 dissertações e 05 teses). Observamos que estas pesquisas não apresentam de forma explícita um currículo pautado em CTS, embora expressem preocupações com alguns aspectos sociais. Nas dissertações aparecem com alta frequência os termos sociedade, transformação e tecnologia; com baixa frequência os termos autonomia, cidadão e cidadania. Nas teses os termos sociedade, transformação, autonomia e tecnologia aparecem em todas as pesquisas, porém os termos cidadão e cidadania têm frequência baixa ou nem aparecem. Podemos concluir que há, de algum modo, a preocupação com uma aprendizagem voltada para a formação social, mas não percebemos a presença da Ciência, Tecnologia e Sociedade claramente desenvolvida no currículo de Matemática na Educação Básica.

Palavras-chave: Currículo, Educação Básica, CTS, matemática.

\section{INTRODUÇÃO}

O avanço das tecnologias provocou alterações na visão de currículo escolar. Nessa perspectiva, o professor está sendo constantemente desafiado a encontrar novas estratégias para um currículo mais dinâmico, flexível e atual.

Com o objetivo de orientar a prática do professor, no Brasil, em 1997, iniciou-se a implementação dos Parâmetros Curriculares Nacionais (PCN). Em dezembro de 2017, a Resolução CNE/CP oo 02 instituiu e orientou a implantação da Base Nacional Comum Curricular (BNCC), com o objetivo de delinear novos rumos para garantir a 
qualidade do ensino, estabelecendo um patamar de aprendizagem e de desenvolvimento que todos alunos têm direito.

A Constituição Federal (Brasil, 1988) em seu artigo 205, estabelece que:

[...] a educação, direito de todos e dever do Estado e da família, será promovida e incentivada com a colaboração da sociedade, visando ao pleno desenvolvimento da pessoa, seu preparo para o exercício da cidadania e sua qualificação para o trabalho. (Brasil, 1988, p.124).

Esta recomendação foi reafirmada no art. $2^{\circ}$ da Lei de Diretrizes e Bases da Educação Nacional - LDB, nos seguintes termos:

A educação, dever da família e do Estado, inspirada nos princípios de liberdade e nos ideais de solidariedade humana, tem por finalidade 0 pleno desenvolvimento do educando, seu preparo para o exercício da cidadania e sua qualificação para o trabalho (BRASIL, 1996, p.8).

A cidadania requer uma nova ordem internacional e uma vigilância sobre a atuação dos especialistas. Dar voz aos cidadãos, através de uma formação CTS que permita aos mesmos agir com racionalidade social e técnico científica é, também, uma possibilidade de tomada de decisões mais coerentes e de formação de sujeitos mais participativos.

Ao incorporar o enfoque CTS no currículo de uma disciplina, o professor deverá contemplar exigências didáticas e epistemológicas. A educação científica baseada em CTS vai para além da dimensão didática da disciplina ensinada, exige uma atenção para a dimensão epistemológica e questões relacionadas com a natureza da ciência a ser ensinada. Das exigências didáticas, destaca-se os conteúdos com focos em contextos significativos, que tenham relevância para a vida, de modo a interagir com conteúdos figurativos, estruturais, semânticos e comportamentais. Da exigência epistemológica, aponta-se para o rompimento do discurso internalista, que serve mais para excluir, marginalizar do que para autorizar o cidadão, ou seja, o aluno.

Nesse contexto, é importante entender o que é currículo, pois ele é que vai nortear as diferentes estratégias de ensino para que se alcance o objetivo desejado na educação. Segundo Sacristán (2000), o currículo é o cruzamento de práticas 
diferentes e se converte em configurador, por sua vez, de tudo o que podemos denominar como prática pedagógica nas aulas e nas escolas.

\section{JUSTIFICATIVA}

Diante dessa realidade, as abordagens, baseadas na problematização de temas sociais, visam propiciar ao desenvolvimento da capacidade da tomada de decisão pelo aluno. Assim a abordagem didática por meio da introdução de problemas propostos em sala de aula após a discussão de alternativas diversas relacionadas aos conteúdos científicos estudados, as aplicações tecnológicas dos mesmos e as consequências sociais (SANTOS; MORTIMER, 2002). Busca-se priorizar uma aprendizagem por meio da problematização do conhecimento científico que permita estabelecer uma relação com o cotidiano do aluno.

Abordamos aqui a disciplina Matemática, relevante para o currículo escolar, numa perspectiva de uma educação com enfoque Ciência, Tecnologia e Sociedade (CTS), cujo objetivo é formar um cidadão crítico e capaz de tomada de decisões cientificamente fundamentadas. Nos documentos oficiais aparecem indicações para a formação desse cidadão. Os PCN, em seus princípios e fundamentos, propõem que a prática educativa "garanta as aprendizagens essenciais para a formação de cidadãos autônomos, críticos e participativos, capazes de atuar com competência, dignidade e responsabilidade na sociedade em que vivem" (BRASIL, 1997, p 27).

Nas Diretrizes Curriculares Nacionais (DCN) da Educação Básica, no que se refere a organização do currículo escolar, encontramos explicitamente informações acerca da interdisciplinaridade e da transversalidade no trabalho pedagógico. (BRASIL, 2013). Uma educação CTS, pelas suas características, é considerada interdisciplinar, Santos (2012) considera que o ensino de ciências numa perspectiva CTS tem seu foco nas relações recíprocas entre ciência, tecnologia e sociedade. O que torna o currículo atual diferente do modelo currículo tradicional. Uma das características da educação CTS é o emprego de materiais curriculares organizados a partir de temas sociais que remetem aos conteúdos científicos da disciplina correlacionados com os conhecimentos tecnológicos o que permite a compreensão dos conceitos da 
disciplina relacionados com uma questão tecnológica, permitindo uma compreensão ampla do problema social inicialmente posto em discussão para os alunos (SANTOS, 2012).

O ensino de Ciências e Matemática numa perspectiva CTS inclui a discussão em sala de aula de temas relacionados as questões econômicas, políticas, sociais, culturais, éticas e ambientais, o que permite ampliar a consciência do papel tanto da Ciência quanto da Tecnologia e da Sociedade. Santos (2007) destaca que os professores de Ciências e Matemática normalmente restringem os temas CTS a simples ilustrações de exemplos das aplicações da tecnologia nas respectivas áreas. Esse fato decorre da resistência e ou da dificuldade enfrentada pelo professor para realização de debates em torno de questões políticas.

Diante o exposto, neste artigo temos o objetivo de mapear e analisar as pesquisas encontradas no banco de dados da Capes, para verificar se nestas havia alguma relação com o desenvolvimento de um currículo de Matemática com enfoque CTS.

\section{METODOLOGIA}

Considerando o exposto, o presente estudo se caracterizou como uma pesquisa qualitativa do tipo estado do conhecimento, que teve como objetivo geral realizar um levantamento das produções científicas sobre o Currículo de Matemática numa perspectiva CTS no período de 2003 a 2018.

O banco de dados da Coordenação de Aperfeiçoamento de Pessoal de Nível Superior (CAPES), armazena Dissertações e Teses; é um espaço onde encontramos as produções dos programas de pós-graduação stricto sensu de universidades públicas e privadas do Brasil. Nosso objetivo neste trabalho foi investigar as teses e dissertações com foco no desenvolvimento de uma aprendizagem de Matemática voltada para uma formação cidadã.

O método conhecido como Estado de Conhecimento tem caráter bibliográfico e permite mapear as produções científicas acerca de um tema em um determinado 
período e discutir acerca da mesma. Procurou-se responder a seguinte questão: Que aspectos e dimensões vêm sendo contemplados e destacados em diferentes épocas e lugares; de que modo e em que condições as teses e dissertações vem sendo produzidas e publicadas (em quais periódicos e ou anais de congressos e seminários).

Como objeto de estudo foi definido o tema "O currículo de Matemática da Educação Básica: uma perspectiva da Ciência, Tecnologia e Sociedade (CTS)". Delimitamos nossa busca ao período entre 2003 a 2018. O propósito foi responder a seguinte questão: Qual é o cenário da pesquisa acadêmica brasileira, sobre currículo de Matemática com a formação CTS?

O mapeamento no banco de dados da Capes foi realizado com o seguinte refinamento: Currículo de Matemática, CTS Matemática e Educação Básica. A princípio realizamos a leitura dos resumos para identificar o foco das produções. Em alguns trabalhos foi necessário ampliar a leitura para entender o contexto da pesquisa e obter informação para caracterizar os trabalhos de acordo com os descritores estabelecidos: ano, tipo de pesquisa - dissertação ou tese, título, nome do autor, instituição de origem. Foi considerada na busca, a Educação Básica envolvendo Anos Iniciais e Anos Finais do Ensino Fundamental, Ensino Médio e a Educação de Jovens e Adultos (EJA). Encontramos alguns trabalhos relacionados ao currículo de Matemática relacionado com a formação do professor. 


\section{ANÁLISE DE DADOS}

Quadro 1: Dissertações Mapeadas pelo Banco da Capes - 2003 a 2018

\begin{tabular}{|c|c|c|c|}
\hline Ano & Título & Autor & Instituição \\
\hline 2003 & $\begin{array}{l}\text { A passagem da } 4^{a} \text { para } 5^{a} \text { série: } O \text { que } \\
\text { pensam professores dessas séries } \\
\text { sobre os conteúdos essenciais de } \\
\text { Matemática }\end{array}$ & $\begin{array}{l}\text { Angelita } \\
\text { Minetto } \\
\text { Araújo }\end{array}$ & UFPR \\
\hline 2006 & $\begin{array}{l}\text { Três décadas de pesquisa em } \\
\text { Educação Matemática na UNICAMP: } \\
\text { um estudo histórico a partir de teses e } \\
\text { dissertações }\end{array}$ & $\begin{array}{l}\text { Marisol Vieira } \\
\text { de Melo }\end{array}$ & UNICAMP \\
\hline 2008 & $\begin{array}{l}\text { O tratamento da informação nas séries } \\
\text { iniciais } \\
\text { Uma proposta de formação de } \\
\text { professores para o ensino de gráficos } \\
\text { e tabelas }\end{array}$ & $\begin{array}{l}\text { Elizangela } \\
\text { Gonçalves de } \\
\text { Araújo }\end{array}$ & UFSC \\
\hline 2009 & $\begin{array}{l}\text { Percepções de professores de } \\
\text { Matemática do EM "São Paulo Faz } \\
\text { escola" Escola": Um Estudo em duas } \\
\text { Escolas de uma Cidade da Grande } \\
\text { São Paulo }\end{array}$ & $\begin{array}{l}\text { Vanderlei } \\
\text { Sanches } \\
\text { Oddi }\end{array}$ & PUC/SP \\
\hline 2012 & $\begin{array}{l}\text { Currículo de Matemática da Educação } \\
\text { de Jovens e Adultos: Análise de } \\
\text { prescrições na perspectiva cultural da } \\
\text { Matemática }\end{array}$ & $\begin{array}{l}\text { Gilberto } \\
\text { Januário }\end{array}$ & PUC/SP \\
\hline 2012 & $\begin{array}{l}\text { O currículo de Matemática prescrito e } \\
\text { o currículo em ação alguns terceiros } \\
\text { anos do ensino fundamental da rede } \\
\text { municipal de educação de Curitiba }\end{array}$ & $\begin{array}{l}\text { Michelle Tais } \\
\text { Faria } \\
\text { Feliciano }\end{array}$ & UFPR \\
\hline 2013 & $\begin{array}{l}\text { Ressignificando o saber docente pelo } \\
\text { olhar da prática pedagógica: um } \\
\text { estudo de professores mestres pela } \\
\text { UEPB }\end{array}$ & $\begin{array}{l}\text { Débora } \\
\text { Cristina } \\
\text { Santos }\end{array}$ & UEPB \\
\hline 2014 & $\begin{array}{l}\text { Professoras das séries iniciais do } \\
\text { ensino fundamental e as orientações } \\
\text { curriculares oficiais para o ensino de } \\
\text { Matemática: um estudo dessa relação }\end{array}$ & $\begin{array}{l}\text { Liane Geyer } \\
\text { Poggetti }\end{array}$ & USP \\
\hline
\end{tabular}


Fundamentada em Bardin (2011), a análise de dados realizada neste estudo envolveu as seguintes etapas: 1) pré-análise, 2) exploração do material e 3) tratamento dos resultados, inferência e interpretação.

$\mathrm{Na}$ pré-análise analisamos e sistematizamos as ideias apontadas pelo referencial teórico e definimos os indicadores para a interpretação das informações coletadas. Esta fase consistiu em uma leitura flutuante do material encontrado e da organização do mesmo afim de possibilitar as operações sucessivas de análise. A leitura flutuante foi o primeiro contato com os documentos encontrados. Após a definição do corpus de análise (escolha dos documentos), formulamos a hipótese e definimos os objetivos que nortearam a elaboração dos indicadores e interpretação do material.

Foram mapeadas 13 produções científicas entre dissertações e teses. Sendo que 8 são dissertações de mestrado e 05 são teses de doutorado. A organização do mapeamento foi distribuída em quadros e gráficos para melhor entendimento e análise.

O Quadro 1 mostra o número de publicações quanto a periodicidade e a instituição. Verificou-se um grande espaçamento na produção de dissertações sobre currículo de Matemática no período de 2003 até 2006 . Em relação a produção por instituição, notase que a maior produção científica é da Universidade Federal do Paraná-UFPR e da Pontifícia Universidade Católica de São Paulo-PUC/SP. 
Quadro 2 - Teses Mapeadas pelo Banco da Capes - 2003 a 2018

\begin{tabular}{|c|c|c|c|}
\hline Ano & Título & Autor & Instituição \\
\hline 2003 & $\begin{array}{l}\text { A vivência da experiência da } \\
\text { prática de ensino de } \\
\text { Matemática }\end{array}$ & $\begin{array}{l}\text { Paulo Isamo } \\
\text { Hiratsuka }\end{array}$ & Unesp/Rio Claro \\
\hline 2008 & $\begin{array}{l}\text { Olhares sobre a formação } \\
\text { do professor de Matemática. } \\
\text { Imagem da profissão e } \\
\text { escrita de si. }\end{array}$ & $\begin{array}{l}\text { Maria José } \\
\text { Medeiros } \\
\text { Dantas de } \\
\text { Melo }\end{array}$ & UFRN \\
\hline 2011 & $\begin{array}{l}\text { Currículo, cultura e } \\
\text { Educação Matemática: Uma } \\
\text { aproximação possível? }\end{array}$ & $\begin{array}{l}\text { Elenilton } \\
\text { Vieira Godoy }\end{array}$ & USP \\
\hline 2016 & $\begin{array}{l}\text { Mapeamento de pesquisas } \\
\text { sobre currículos de } \\
\text { Matemática na Educação } \\
\text { Básica Brasileira (1987 a } \\
\text { 2012) }\end{array}$ & $\begin{array}{l}\text { Wagner } \\
\text { Barbosa de } \\
\text { Lima Palanch }\end{array}$ & PUC/SP \\
\hline 2018 & $\begin{array}{l}\text { "Como você chegou a esse } \\
\text { resultado?": O diálogo nas } \\
\text { aulas de Matemática dos } \\
\text { Anos Iniciais do Ensino } \\
\text { Fundamental }\end{array}$ & $\begin{array}{l}\text { Ana Carolina } \\
\text { Faustino }\end{array}$ & UNESP/Rio Claro \\
\hline
\end{tabular}

Fonte: Dados da Pesquisa

No quadro 2 mostramos o ano de publicação das teses, evidenciando a escassez de produção no que tange ao currículo de Matemática. Das diferentes instituições houve uma produção com a temática "currículo", mas por anos não consecutivos. $\mathrm{Na}$ Universidade Estadual de São Paulo-UNESP/Rio Claro, constatamos produções somente em 2003 e 2018.

Os gráficos 1 (dissertações), 2 (teses) mostram as pesquisas mapeadas e organizadas por nível de ensino, sendo: Anos Iniciais do Ensino Fundamental, Anos Finais do Ensino Fundamental, Ensino Médio, Educação de Jovens e Adultos (EJA) e no Ensino Superior (formação de professores). 
Gráfico 1 - Organização das Dissertações por etapa e modalidade de ensino.

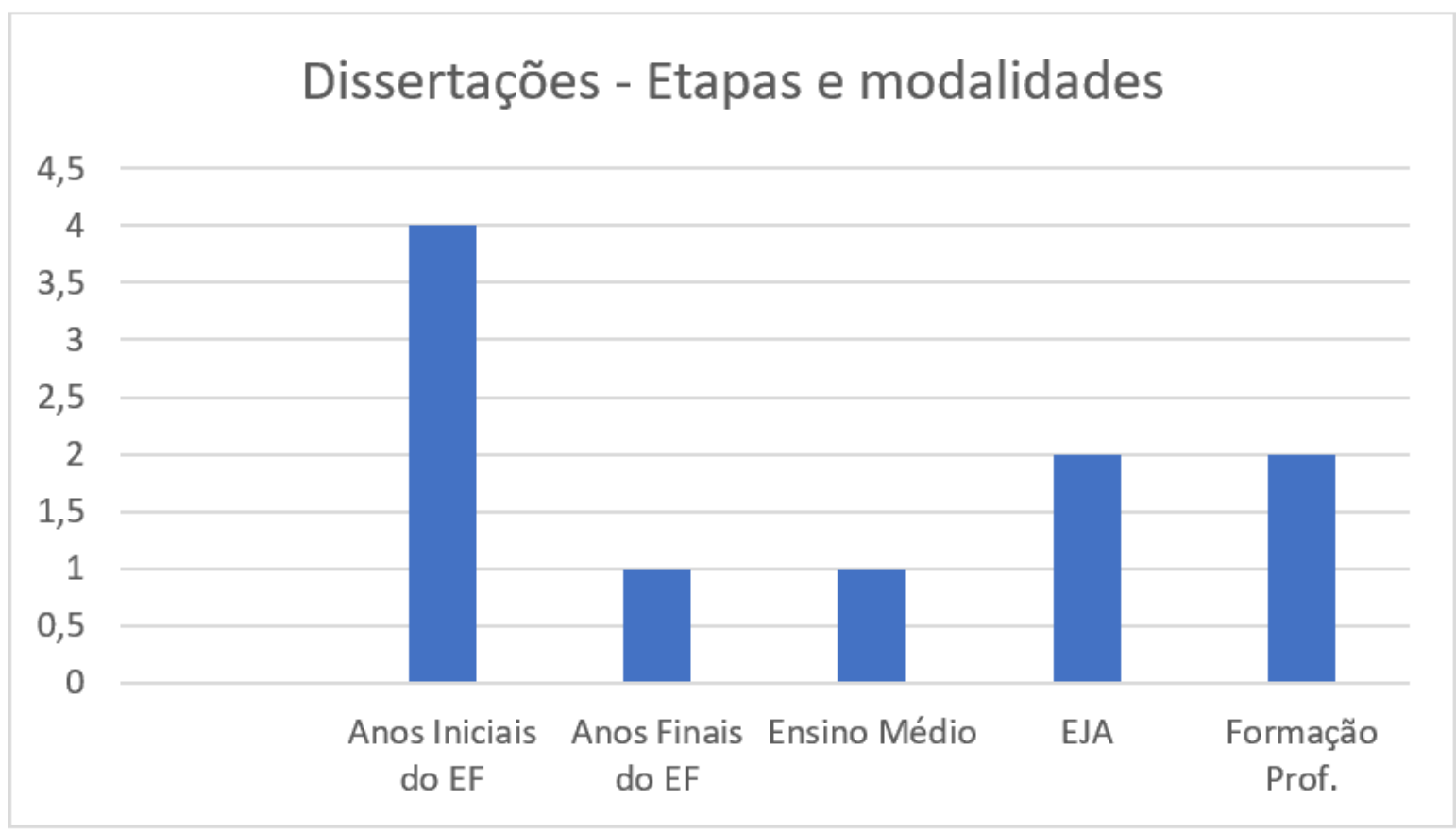

Fonte: Dados da Pesquisa

O gráfico 1 representa a distribuição das pesquisas de mestrado (dissertação). O nível em que mais pesquisas foram realizadas foi Anos Iniciais do Ensino Fundamental: 04 (quatro) pesquisas. No Ensino Médio identificamos 02 (duas) pesquisas, nos Anos Finais do Ensino Fundamental somente 01 (uma) pesquisa na modalidade da Educação de Jovens e Adultos (EJA) também 01 (uma) pesquisa. No ensino superior identificamos 02 (duas) pesquisas abordando a formação de professores para os Anos Iniciais do Ensino Fundamental. 
Gráfico 2 - Organização das Teses por etapa e modalidade de ensino:

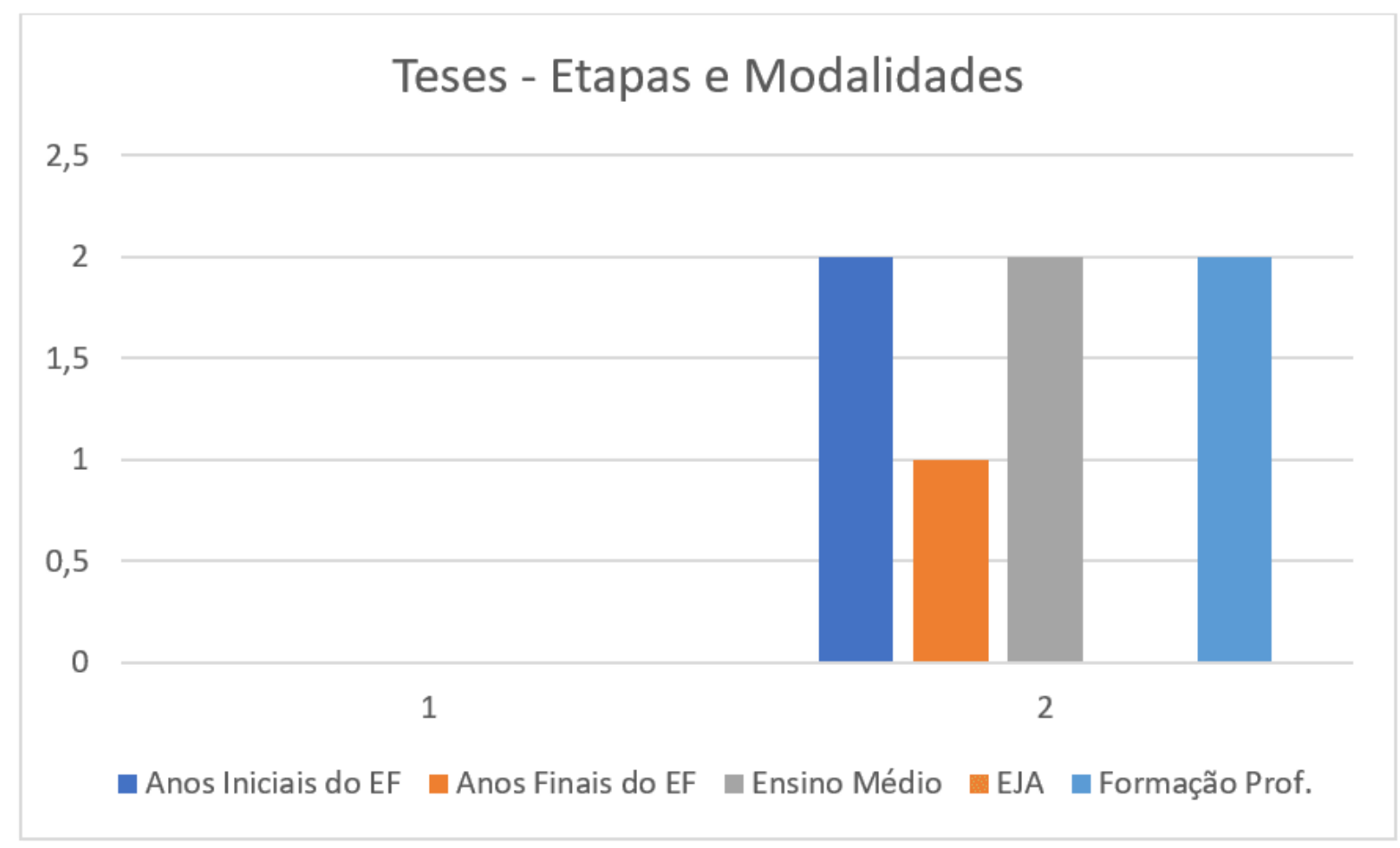

Fonte: Dados da Pesquisa

No gráfico 2 verificou-se nas teses mapeadas, 02 (duas) referiam-se aos Anos Iniciais do Ensino Fundamental, 01 (uma) dos Anos Finais do Ensino Fundamental, 02 (duas) no Ensino Médio e (02) no Ensino Superior acerca do Currículo na formação de professores. Nenhuma das teses apresentadas tratou do assunto na modalidade EJA. Outro fato interessante foi que na pesquisa de Melo (2008) o tema currículo é mencionado nos Anos Iniciais do Ensino Fundamental e na formação de professores. A pesquisa de Palanch (2016) trata da pesquisa sobre currículo de Matemática de 1987 a 2012.

Nas produções mapeadas neste artigo, destacamos o objeto de pesquisa de cada uma por ordem cronológica.

A tese de Hiratsuka (2003) tratou o currículo na perspectiva da prática do professor, questionando modelos empregados no fazer matemático. Os professores investigados questionavam o modelo do ensino tradicional de Matemática com o qual eles foram ensinados e que reproduziam em suas aulas. Este autor relata que: 
Estava, então, em torno de uma interrogação que solicitava, e, portanto, apontava para uma leitura abrangente sobre o ensino de Matemática, a qual me levou a compreender que nesse ensino estão envolvidas concepções de mundo, sociedade, homem, Educação, conhecimento, Matemática. (HIRATSUKA, 2003, p. 12).

A dissertação de Araújo (2003) abordou a manifestação de duas professoras sobre conteúdos considerados essenciais na passagem dos Anos Iniciais para os Anos Finais do Ensino Fundamental, (antiga 4를 série para $5^{a}$. série). Relata as experiências das professoras no período de formação e as dificuldades nos conteúdos de Matemática.

A dissertação de Melo (2006) resgatou o processo histórico da constituição e da pesquisa acadêmica em Educação Matemática. Enfatizou a formação de pesquisadores em Educação Matemática e a formação de formadores de professores de Matemática; a quantidade de estudos desenvolvidos em relação à psicologia na Educação Matemática (atitudes, aprendizagens e desenvolvimento conceitual, cognitivo e de habilidades) e à prática pedagógica em Matemática e/ou formação de professores que ensinam Matemática; à história, filosofia, epistemologia e cultura (etnomatemática) da/na Educação Matemática.

A tese de Melo (2008), que teve como foco a formação do professor no Ensino Superior, evidenciou que o início da carreira docente dos participantes foi marcado por práticas mecânicas, influenciadas pelas modelos de professor que eles vivenciaram.

A pesquisa de Araújo (2008) incidiu diretamente na formação de professores pedagogos acerca da problemática do ensino e aprendizagem de gráficos e tabelas nos Anos Iniciais do Ensino Fundamental. Considera a sugestão dos PCN a respeito do tratamento da informação, bem como a proposta curricular do Estado de Santa Catarina, situando o aporte teórico na noção de Registro de Representação Semiótica (RRS) de Raymond Duval para a aprendizagem em Matemática.

Oddi (2009), em sua dissertação, investigou as percepções de professores do Ensino Médio sobre o Projeto São Paulo faz Escola, privilegiando o que revelam a respeito 
do seu processo de implementação. As questões centrais da pesquisa foram o que destacam os professores a respeito da proposta curricular no que se refere a sua implementação. Os professores relatam seus sentimentos em relação a maneira de abordar os conteúdos de Matemática a partir da proposta do Governo de São Paulo.

A tese de Godoy (2011), apresentou um estudo de Currículos no ensino e aprendizagem em Matemática, realizado do Grupo de Estudos e Pesquisa em Educação Matemática e Educação (GEPEME), da área de Ensino de Matemática e Ciências do Programa de Estudos Pós-Graduados em Educação da Faculdade de Educação da Universidade de São Paulo (USP), o objetivo desta pesquisa foi investigar em que medida o conhecimento Matemático era utilizado na sociedade contemporânea e como se manifesta nas relações de poder; compreender sobre e como as práticas de significação interferem na organização e construção do currículo da Matemática da Educação Básica.

A dissertação de Januário (2012) aborda o ensino de Matemática da EJA. O autor selecionou como exemplo de currículo prescrito a Proposta Curricular para o segundo segmento para a EJA do Ensino Fundamental; selecionou o volume I (Introdução) e Volume 3 (Matemática) afim de investigar as Propostas Curriculares da EJA que possibilitasse uma aproximação da cultura formal com uma cultura informal da Matemática; quais as características de enculturação eram apresentadas por este currículo; quais os critérios adotados em relação à organização dos conteúdos; quais as opções sugeridas para a escolha de contextos?

Feliciano (2012) em sua dissertação cujo objetivo compreender as convergências e divergências, em relação aos níveis de relevâncias considerados ao conteúdos de Matemática presente nos documentos oficiais e na prática de professores do 3.ำ ano do Ensino Fundamental da Rede Municipal de Educação de Curitiba; conhecer, documentar e compreender as convergências e divergências no que diz respeito: níveis de relevância dos conteúdos, prática dos professores e justificativas dadas pelos mesmos para eventuais divergências. 
Poggetti (2014) realizou uma dissertação em que discutiu a prática de ensino da Matemática, as concepções e o modo de ensinar sugeridos pelos programas curriculares oficiais; dos saberes e concepções decorrentes da sua própria prática enquanto professor pesquisador, englobando sua formação inicial e sua prática docente; o papel da formação continuada de docentes em que os mesmo lecionam, cujo propósito é prepara-los para lidar com as Orientações Curriculares oficiais para o Ensino de Matemática.

Palanch (2016), em sua tese, investigou e analisou a produção acadêmica sobre currículos de Matemática do período de 1987 a 2012, de forma a estudar e compreender a configuração desta temática no campo da Educação Matemática.

Faustino (2018), desenvolveu uma tese cujo objetivo foi compreender como estudantes e professores dialogam nas aulas de Matemática dos Anos Iniciais do Ensino Fundamental; a fim de identificar elementos que favoreçam a construção de uma aula de Matemática dialogada.

Para obtenção desses dados utilizamos a ferramenta do word - "localizar", com o objetivo de verificar a frequência de alguns termos considerados importantes para verificar se cada pesquisa mapeada tinha uma perspectiva CTS. Os termos localizados em cada pesquisa, tanto nas dissertações quanto nas teses, foram: autonomia, cidadão, cidadania, sociedade, tecnologia e transformação. Os resultados de cada termo localizado nas pesquisas estão representados em gráficos.

O gráfico 3 representa o número de frequência dos termos nas dissertações e o gráfico 4 , representa o número de frequência dos termos localizados nas teses. 
Gráfico 3: Dissertações

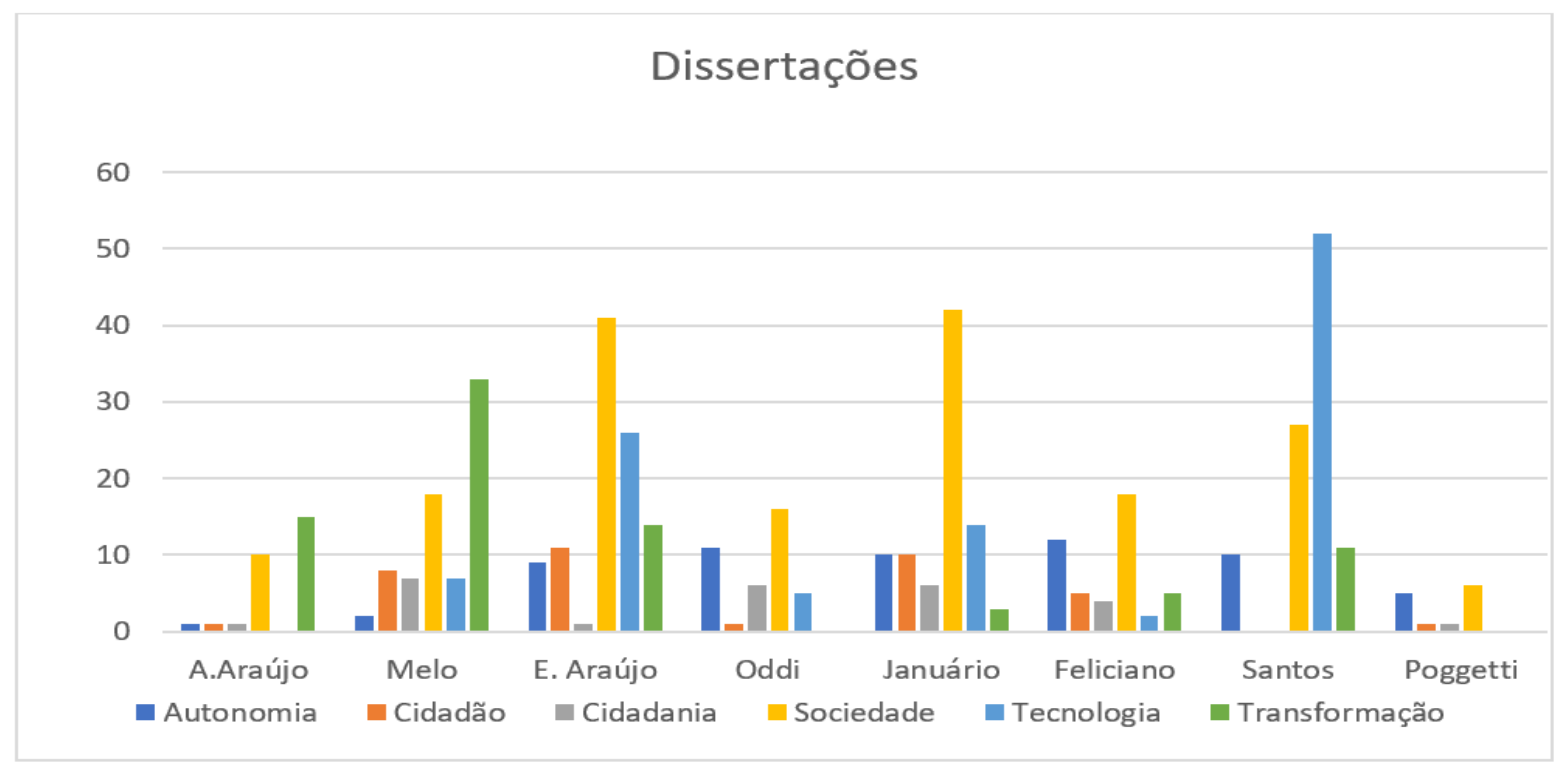

Fonte: Dados da Pesquisa

No gráfico 3 percebe-se que os termos que mais aparecem nas pesquisas são: sociedade, transformação e tecnologia. Os termos autonomia, cidadão e cidadania aparecem na maioria das pesquisas, porém com frequência baixa.

\section{Gráfico 4: Teses}

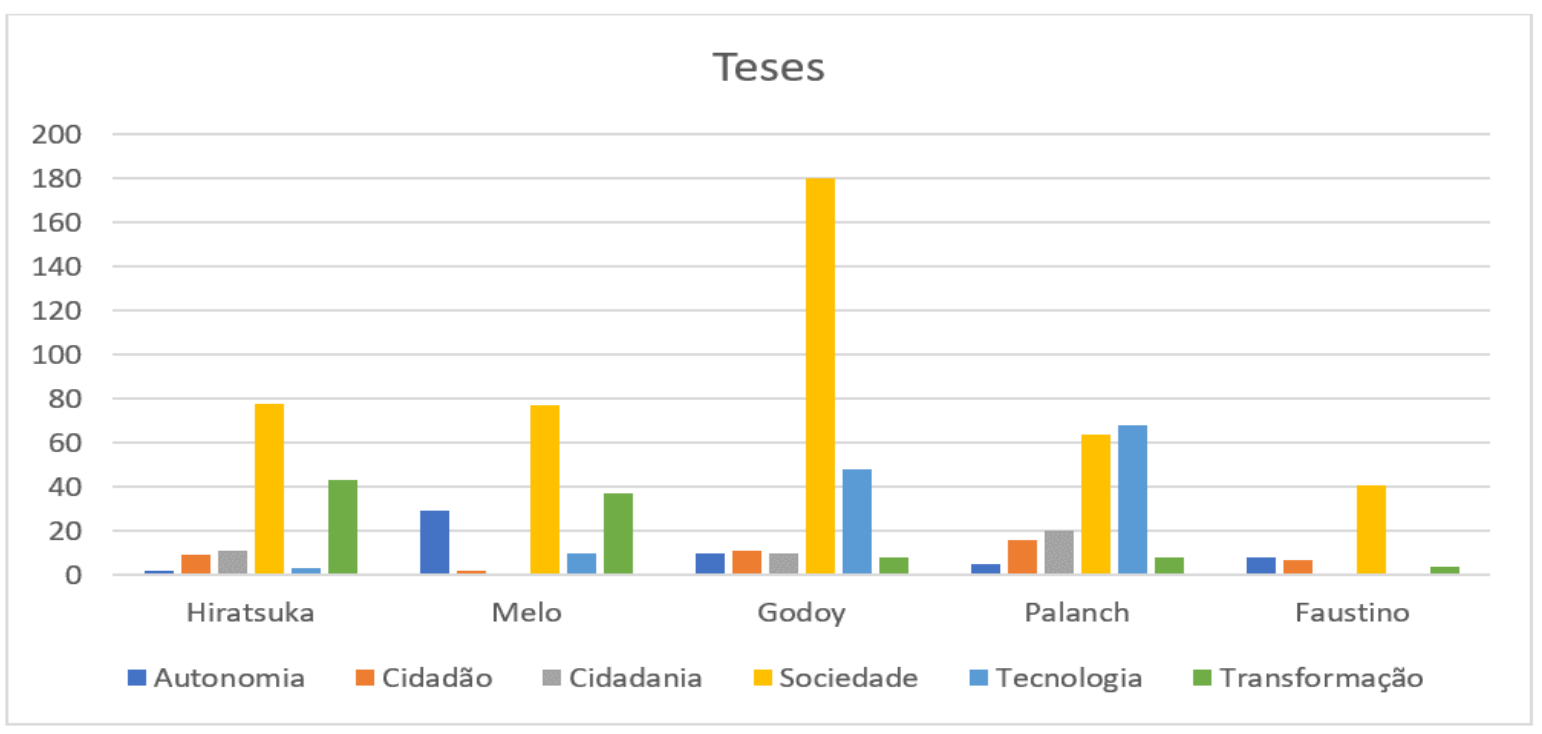

Fonte: Dados da Pesquisa

RC: 57570

Disponível em: https://www.nucleodoconhecimento.com.br/educacao/curriculo-de-matematica 
No gráfico 4 fica explicitada a presença dos termos sociedade, seguida de transformação, autonomia e tecnologia. Os termos cidadão e cidadania quase não aparecem nas pesquisas.

\section{CONSIDERAÇÕES FINAIS}

Neste artigo procuramos responder a seguinte pergunta: Qual é o cenário da pesquisa acadêmica brasileira, sobre currículo de Matemática com a formação CTS? Após fazer uma análise das pesquisas desde a Educação Básica até a formação de professores, verificamos que o banco de teses e dissertações da Capes apontou um total 13 (treze) produções científicas. Realizamos uma leitura inicial dos títulos e resumos, nos deparamos com alguns termos relacionados a uma formação CTS. Embora haja muitas pesquisas que envolvam o termo currículo, não identificamos pesquisas exclusivas relacionadas ao currículo de Matemática com formação CTS. Este estudo demonstrou que as pesquisas tendem a pensar num currículo centrado na cidadania.

No gráfico 3 que representa a análise das dissertações, podemos perceber que os termos que mais aparecem nas pesquisas são: sociedade, transformação e tecnologia. Os termos autonomia, cidadão e cidadania aparecem na maioria das pesquisas, porém com frequência baixa.

No gráfico 4, que apresenta a análise das teses, é nítida a presença dos termos sociedade, seguido de transformação, autonomia e tecnologia. Os termos cidadão e cidadania quase não aparecem nas pesquisas.

Retomando os objetivos do ensino de Matemática, temos nos PCN a indicação de um currículo que possa contribuir para a valorização da pluralidade sociocultural minimizando o processo de submissão no confronto com outras culturas; criar condições para que o aluno possa transcender um modo de vida próprio do seu espaço social e tornar-se um cidadão ativo na transformação desse ambiente.

No que se refere a um currículo de Matemática com perspectiva CTS na Educação Básica, considera-se necessário repensar a formação do professor para que este 
possa promover situações envolvendo os alunos com aspectos relacionados a Ciência, Tecnologia e Sociedade; para que se construa coletivamente num ambiente escolar organizado para usar o senso crítico para resolver problemas sociais. Segundo Santos e Mortimer (2002), um currículo com enfoque CTS tem por objetivo geral preparar os alunos para o exercício da cidadania, assim a abordagem dos conteúdos científicos devem estar relacionados com o contexto social. Esperase que estes apontamentos, sirvam para futuros debates e pesquisa relacionados aos processos de ensino de Ciências e Matemática pautados no desenvolvimento de uma postura mais crítica de professores e alunos envolvidos com o papel da Ciência e das Tecnologias na sociedade atual.

\section{REFERÊNCIAS}

ARAUJO, Angelita Minetto. A passagem da 4⿳亠丷. para 5a. série: 0 que pensam professores dessas séries sobre os conteúdos essenciais de Matemática. 2003. 226 f. Dissertação (Mestrado em Educação Matemática) - Faculdade de Educação, Universidade Federal do Paraná, Paraná, 2003.

ARAUJO, Elizangela Gonçalves de. 0 tratamento da informação nas séries iniciais. Uma proposta de formação de professores para o ensino de gráficos e tabelas. 2008. 177 f. Dissertação (Mestrado em Educação Científica e Tecnológica) - Centro de Ciências Físicas e Matemáticas - Universidade Federal de Santa Catarina, Florianópolis, 2008.

BARDIN, L. Análise de conteúdo. Lisboa: Edições 70, 2011.

BRASIL. Constituição da República Federativa do Brasil de 1988. Brasília, DF: Presidência da República, [2016]. Disponível em: https://www2.senado.leg.br/bdsf/bitstream/handle/id/518231/CF88_Livro_EC91_201 6.pd: Acesso em 3 jan. 2020.

. Diretrizes Curriculares Nacionais Gerais da Educação Básica. Brasília: MEC/SEB, 2013. 
. Base Nacional Comum Curricular. Brasília: MEC, 2017. Disponível em: http://basenacionalcomum.mec.gov.br/

Secretaria de Educação Fundamental. Parâmetros curriculares nacionais: matemática / Secretaria de Educação Fundamental. - Brasília: MEC/SEF, 1997.

. LDB : Lei de Diretrizes e Bases da Educação Nacional. - 3. ed. - Brasília: Senado Federal, Coordenação de Edições Técnicas, 2019. 59 p. Disponível em:https://www2.senado.leg.br/bdst/handle/id/559748: Acesso em 10 jan.2020.

Resolução CNE/CP № 2, de 22 de Dezembro de 2017. Brasília: MEC/SEB, 2017 Disponível

em:

http://portal.mec.gov.br/index.php?option=com_docman\&view=download\&alias=7963 1-rcp002-17-pdf\&category_slug=dezembro-2017-pdf\&ltemid=30192: Acesso em 15 jan.2020

FAUSTINO, Ana Carolina. "Como você chegou a esse resultado?": O diálogo nas aulas de Matemática dos Anos Iniciais do Ensino Fundamental. 2018. $232 \mathrm{f}$. Tese (Doutorado em Educação Matemática) - Instituto de Geociências e Ciências Exatas, Universidade Estadual Paulista, Rio Claro, 2018.

FELICIANO, Michelle Taís Faria. O currículo de matemática prescrito e o currículo em ação alguns terceiros anos do ensino fundamental da rede municipal de educação de Curitiba. 2012. 226 f. Dissertação (Mestrado em Educação em Ciências e Matemática) - Setor de Ciências Exatas - Universidade Federal do Paraná, Curitiba, 2012.

GODOY, Elenilton Vieira. Currículo, cultura e Educação Matemática: Uma aproximação possível? 2011. $201 \mathrm{f}$. Tese (Doutorado em Ensino de Ciências e Matemática) - Faculdade de Educação, Universidade de São Paulo, São Paulo, 2011. 
HIRATSUKA, Paulo Isamo. A vivência da experiência da prática de ensino de Matemática. 2003. 492 f. Tese (Doutorado em Educação Matemática) - Instituto de Geociências e Ciências Exatas, Universidade Estadual Paulista, Rio Claro, 2003.

JANUARIO, Gilberto. Currículo de Matemática da Educação de Jovens e Adultos: Análise de prescrições na perspectiva cultural da Matemática. 2012. 157 f. Dissertação (Mestrado em Educação Matemática) - Faculdade de Educação, Pontifícia Universidade Católica de São Paulo, São Paulo, 2012.

MELO, Maria José Medeiros Dantas de. Olhares sobre a formação do professor de Matemática. Imagem da profissão e escrita de si. 2008. 323 f. Tese (Doutorado em Educação) - Centro de Ciências Sociais Aplicadas, Universidade Federal do Rio Grande do Norte, Natal, 2008.

MELO, Marisol Vieira. Três décadas de pesquisa em Educação Matemática na UNICAMP: um estudo histórico a partir de teses e dissertações. 2006, $273 \mathrm{f}$. Dissertação (Mestrado em Educação Matemática) - Faculdade de Educação Universidade Estadual de Campinas, Campinas, 2006.

ODDI, Vanderlei Sanches. Percepções de professores de Matemática do EM "São Paulo Faz escola": Um Estudo em duas Escolas de uma Cidade da Grande São Paulo. 2009. 127 f. Dissertação (Mestrado em Educação Matemática) - Faculdade de Educação, Pontifícia Universidade Católica de São Paulo, São Paulo, 2009.

PALANCH, Wagner Barbosa de Lima. Mapeamento de pesquisas sobre currículos de Matemática na Educação Básica Brasileira (1987 a 2012). 2016. 297 f. Tese (Doutorado em Educação Matemática) - Pontifícia Universidade Católica de São Paulo, São Paulo, 2016.

POGGETTI, Liane Geyer. Professoras das séries iniciais do ensino fundamental e as orientações curriculares oficiais para o ensino de Matemática: um estudo dessa relação. 2014. 107 f. Dissertação (Mestrado em Educação de Ciências e Matemática) - Faculdade de Educação - Universidade de São Paulo, São Paulo, 2014. 
SACRISTAN José Gimeno. 0 currículo: uma reflexão sobre a prática. 3. Ed. Porto Alegre: Artmed, 2000.

SACRISTÁN, José Gimeno. Currículo e diversidade cultural. In: SILVA, Tomaz Tadeu da. \& MOREIRA, Antonio Flávio. (Orgs.) Territórios contestados: o currículo e os novos mapas políticos e culturais. Petrópolis: Vozes, p.82-113, 1995.

SANTOS Debóra Cristina. Ressignificando o saber docente pelo olhar da prática pedagógica: um estudo de professores mestres pela UEPB. 2013. $163 \mathrm{f}$. Dissertação ( Mestrado Profissional em Ensino de Cências e Matemática) - Centro de Ciências e Tecnologia - Universidade Estadual da Paraíba, Campina Grande, 2013.

SANTOS, Wildson Luiz Pereira dos. Educação CTS e cidadania: confluências e diferenças. Amazônia. Revista de Educação em Ciências e Matemáticas. V. 9, n. 17, 2012, p.49-62.

SANTOS, Wildson Luiz Pereira dos. MORTIMER, Eduardo Fleury. Uma análise de pressupostos teóricos da abordagem C-T-S (Ciência - Tecnologia - Sociedade) no contexto da educação brasileira. Revista Ensaio- Pesquisa em Educação em Ciência, n. 2, v. 2, dez. 2002.

SILVA, Débora Janaína Ribeiro e. Abordagem CTS e ensino de matemática crítica: um olhar sobre a formação inicial dos futuros docentes. 2012. 167 f. Dissertação (Mestrado em Ensino de Física) - Universidade Estadual da Paraíba, Campina Grande, 2012.

Enviado: Março, 2020.

Aprovado: Agosto, 2020. 